\title{
Prevalence of Root Canal Configuration of Mandibular Second Molar Using Cone-Beam Computed Tomography in a Sample of Iraqi Patients
}

\author{
Hiwa S. Khidir ${ }^{\star *}$, Saud J. Dizayee ${ }^{2}$, Sangar H. Ali ${ }^{3}$ \\ ${ }^{1}$ Department of Dental Assistant, Erbil Technical Medical Institute, Erbil Polytechnic University, Erbil, Kurdistan Region, Iraq, ${ }^{2}$ Department of \\ Conservative Dentistry, Khanzad Teaching Center, Erbil Directorate of Health, Ministry of Health, Erbil, Kurdistan Region, Iraq, ${ }^{3}$ Department of \\ Dental Radiology, Khanzad Teaching Center, Erbil Directorate of Health, Ministry of Health, Erbil, Kurdistan Region, Iraq
}

\begin{abstract}
${ }^{*}$ Corresponding author:
Hiwa S. Khidir, Department of Dental Assistant, Erbil

Technical Medical Institute, Erbil Polytechnic University, Erbil, Kurdistan Region, Iraq. E-mail: hiwa.saeed@yahoo. com
\end{abstract}

Received: 10 May 2020

Accepted: 09 August 2020

Published: 30 June 2021

DOI

10.25156/ptj.v11n1y2021.pp22-26

\section{A B S T R A C T}

Introduction: The purpose of this study was to find out the prevalence of C-shaped canals configurations in mandibular $2^{\text {nd }}$ molar and to investigate the gender prevalence. Materials and Methods: A sample of 1200 patients' cone beam computed tomography (CBCT) scans were screened and evaluated by a maxillofacial radiologist assessed the axial, sagittal, and coronal sections. Inclusion criteria applied to 801 patients ( 452 females and 349 male) aged $14-75$ years were included in this study with total of 1567 mandibular $2^{\text {nd }}$ molar was evaluated. Inclusion criteria: Available CBCT images of mandibular posterior teeth with at least one mandibular $2^{\text {nd }}$ molar in the scan, absence of root canal treatment, absence of coronal or post coronal restorations, absence of root resorption or periapical lesions, and high-quality images. Canal configuration was classified by criteria's which described by Fan et al. (2004): (i) Fused roots, (ii) a longitudinal groove on the buccal or lingual surface of the root, and (iii) at least one cross-section of the canal belongs to the $\mathrm{C} 1, \mathrm{C} 2$, or $\mathrm{C} 3$ configuration. Results: Considering 801 patients, $97(12.1 \%)$ patients females $57(7.1 \%)$ and $40(5 \%)$ males had a C-shaped canal with no statistical difference between females and males $(P>0.05)$. Conclusion: The occurrence of $C$ - shaped canal mandibular $2^{\text {nd }}$ molar is approximately $12.1 \%$ and no significant difference was found by gender.

Keywords: C-shaped canal; Cone-beam computed tomography; Mandibular $2^{\text {nd }}$ molar; Root canal morphology; Root canal treatment

\section{INTRODUCTION}

C-shaped canal morphology is based on the cross section of the root and canal which resembles the shape of a letter C (Fan et al., 2004). As it would be expected, this morphological complexity creates considerable challenges with respect to debridement, disinfection and canal filling procedures, which eventually may influence the prognosis of the root canal treatment (Amoroso-Silva et al., 2015).

Historically, the presence of C-shaped canal anatomy in teeth was first identified in the $18^{\text {th }}$ century (Malpighi, 1743; Hunter and Combe, 1778) and described in details at the beginning of the $20^{\text {th }}$ century (Keith and Knowles, 1911; Keith, 1913). However, it took several decades of technological improvement in endodontics until this knowledge could be applied for the efficient clinical management of C-shaped anatomy (Cooke and Cox, 1979).

Etiology of C-shaped canal belongs to failure of the Hertwig's epithelial root sheath to fuse on the buccal or lingual root surface is the main cause of C-shaped roots, which always include a C-shaped canal. The C-shaped root may also be formed by coalescence because of deposition of the cementum with time (Manning, 1990).

Cone beam computed tomography (CBCT) considered to be sufficient precisely to perform root canal morphological analysis and is a valuable tool to evaluate the C-shaped root canal configuration in vivo (Neelakantan et al., 2010; Zhang et al., 2011; von Zuben et al., 2017). Its features allow the clinician a more profound understanding of true morphology of the root canal systems (Wang et al., 2010).

The prevalence of a C-shaped canal in mandibular $2^{\text {nd }}$ molars has been estimated to range from $2.7 \%$ to $44.5 \%$, depending on the population and ethnic groups: $2.7-7.6 \%$ for American (Cooke and Cox, 1979; Weine, 1998), 3.5\% for Brazilian population (Silva, 2013), 8\% for Turkish (Cimilli et al., 2005; Helvacioglu-Yigit and Sinanoglu, 2013), $10.6 \%$ for Saudi Arabian (Al-Fouzan, 2002), 19.1\% for Lebanese (Haddad et al., 1999), 31.5\% for Chinese (Yang et al., 1988), and $32.7-44.5 \%$ for Korean populations (Seo and Park, 2004; Jin et al., 2006). 
Understanding of root canal anatomy and variation between ethnic groups is a fundamental for clinicians to assist carrying out an effective root canal treatment (RCT) (Vertucci, 1984).

The aim of this study was to use CBCT images to evaluate the prevalence of $\mathrm{C}$-shaped canals in the permanent mandibular $2^{\text {nd }}$ molars of members of an Iraqi Kurdish subpopulation and its prevalence in accordance to gender.

\section{MATERIALS AND METHODS}

Evaluation was made for the radiographs of the patients' mandibular $2^{\text {nd }}$ molars who were referred to DENTA Radiologic Center at Erbil, Kurdistan region, Iraq between 2013 and 2015, regardless of gender or age, thus characterizing a convenience sample.

The inclusion criteria were as follows:

1. Mandibular second molars with fully developed roots

2. No periapical lesions

3. No root canal treatment

4. No roots with open apices or resorption, no root canals with calcification

5. CBCT images of a good quality.

A sample of 1200 patients' CBCT images were screened and evaluated by a maxillofacial radiologist. Inclusion criteria applied to 1567 mandibular $2^{\text {nd }}$ molar which belongs to 801 patients (452 females and 349 male) aged 14-75 years. The images were analyzed for unilateral and/ or bilateral occurrences of C-shaped canals.

The CBCT images were performed using NewTom GiANO CBCT (Bologna, Italy), operating at high frequency 60-90 $\mathrm{KV}$; 1-10 MA pulse mode and $0.5 \mathrm{~mm}$ focal spot. All CBCT exposures were taken by an appropriately licensed radiologist.

NNT software was used to analyze the CBCT images. The brightness and contrast of the images were adjusted using the image processing tool in the software to insure the optimal visualization in the axial sections of the roots. The images were evaluated by a maxillofacial radiologist with 5 years' experience in performing CBCT under suitable light conditions.

Determining of the C-shaped canal configuration in a mandibular $2^{\text {nd }}$ molar required that the tooth manifest all of the following features listed from those described by Fan et al. (2004).

i. Fused roots,

ii. A longitudinal groove on the lingual or buccal surface of the root iii. At least one cross-section of the canal belongs to the $\mathrm{C} 1, \mathrm{C} 2$, or $\mathrm{C} 3$ configuration.

Fan's Classification (Anatomic Classification): Fan et al., in 2004 classified the $\mathrm{C}$-shaped canal configuration into the following categories:

1. Category I (C1): The shape was an interrupted "C" with no separation or division [Figure 1a]

2. Category II (C2): The canal shape resembled a semicolon resulting from a discontinuation of the "C" outline [Figure 1b], but either angle $\dot{\alpha}$ or $\beta$ [Figure 2] should be no less than $60^{\circ}$

3. Category III (C3): Two or three separate canals [Figure $1 \mathrm{c}$ and $\mathrm{d}]$ and both angles, $\dot{\alpha}$ and $\beta$, were less than $60^{\circ}$ [Figure 3]

4. Category IV (C4): Only one round or oval canal in that cross-section [Figure 1e]

5. Category V (C5): No canal lumen could be observed (which is usually seen near the apex only) [Figure 1f].

A succession of axial images from the cervical third to the apical third of the root used to assess the presence of $\mathrm{C}$-shaped canals. Figure $4 \mathrm{a}$ and $\mathrm{b}$ exhibits an example of a tooth considered as having a C-shaped canal, because it exhibits fused roots along the entire length of the root, a longitudinal groove on the buccal surface of the root, and at least one axial section of the canal that shows the C-shaped canal configuration as indicated by the arrows. While another tooth root as in Figure 5a exhibits a root that fused from the cervical third but it is separated at the apical third of the root [Figure 5b], in this case that tooth not classified as $\mathrm{C}$-shaped canal.

\section{Statistical Analysis}

Data were analyzed using IBM SPSS version 25. Descriptive statistics (e.g. number and percentage) were used to represent prevalence of C-shape canal. Pearson's Chisquare test performed to assess the frequency of the

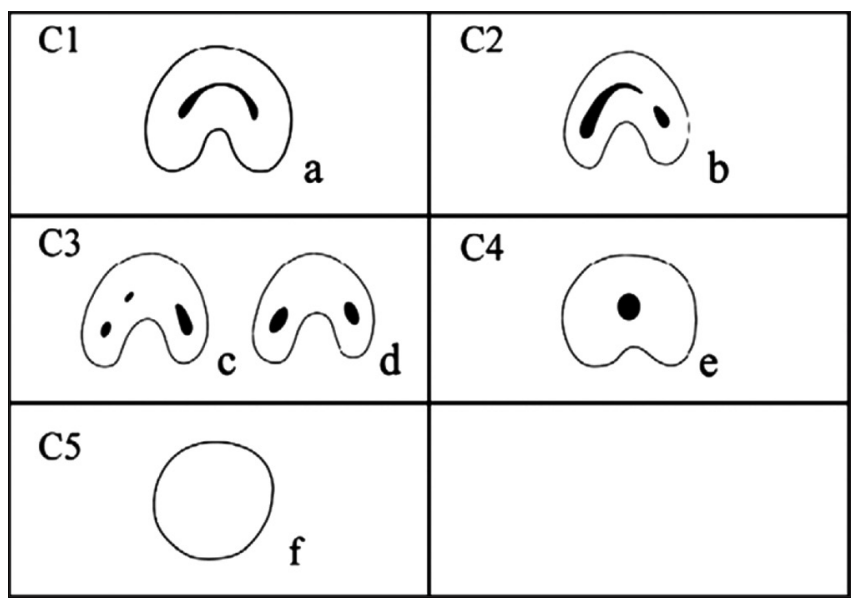

Figure 1: Classification of C-shaped canal configuration (Fan et al., 2004) 
numbers of C-shaped canals and the correlations with gender at significant level of $\alpha=0.05$.

\section{RESULTS}

Table 1 summarizes the overall results (in number and percentage) of the prevalence of $\mathrm{C}$-shaped canal

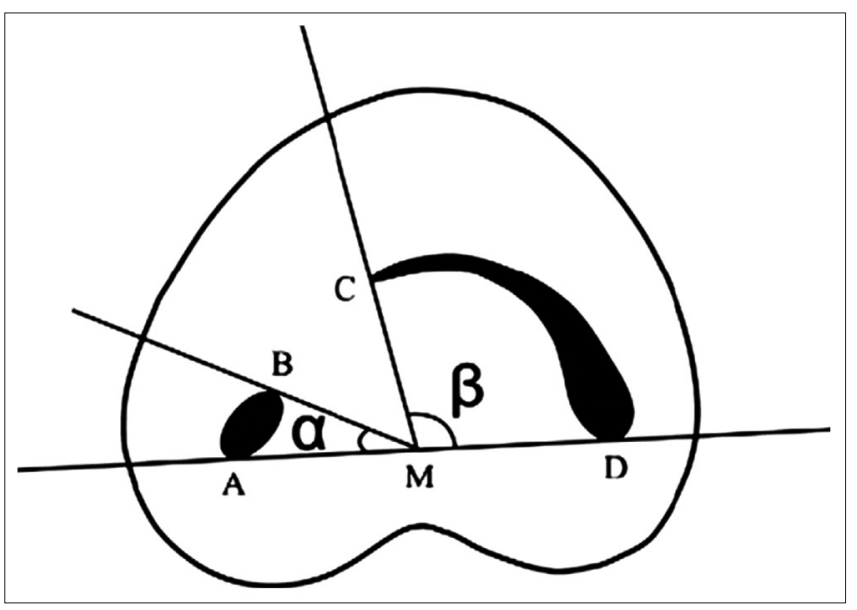

Figure 2: Measurement of angles for the $\mathrm{C} 2$ canal. Angle $\beta$ is more than $60^{\circ}$. (A and B) Ends of one canal cross-section, (C and D) ends of the other canal cross-section; M, middle point of line AD; $\dot{\alpha}$, angle between line $\mathrm{AM}$ and line $\mathrm{BM} ; \beta$, angle between line $\mathrm{CM}$ and line DM (Fan et al., 2004)

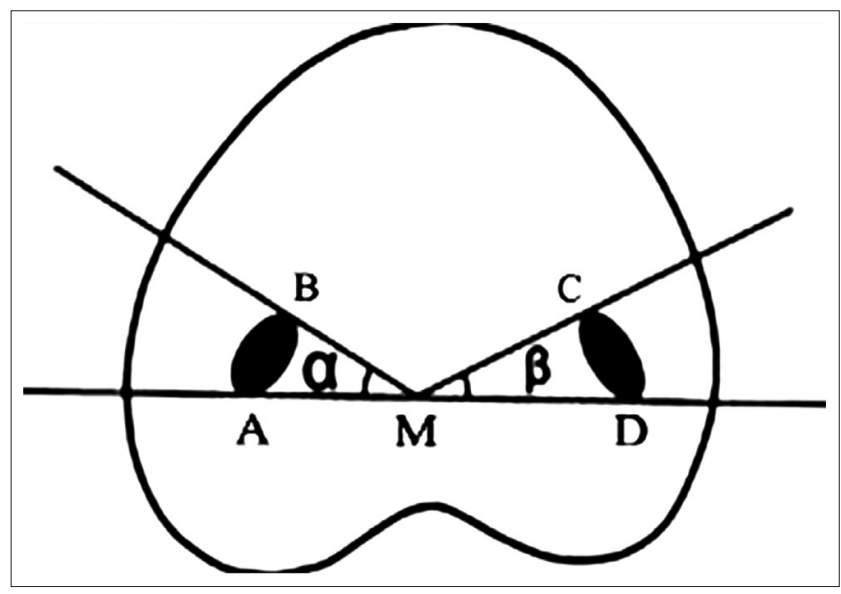

Figure 3: Measurement of angles for the C3 canal. Both angle $\alpha$ and angle $\beta$ are less than $60^{\circ}$ (Fan et al., 2004)

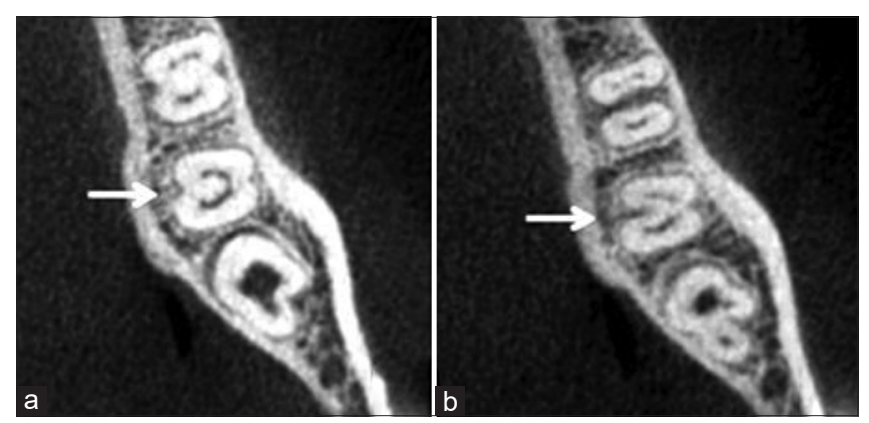

Figure 4: Succession of axial images of a mandibular second molar root. (a) C-shaped canal at cervical third. (b) C-shaped canal at apical third in mandibular second molars in which 801 patients had mandibular second molars (unilateral and/or bilateral) with inclusion criteria examined in CBCT images, 97 (12.1\%) patients had a C-shaped root canal configuration and 704 patients (87.9\%) without C-shaped canal. On the other hand, also as illustrated by Bar chart (Figure 6), the prevalence in accordance to the gender, $57(7.1 \%)$ females were presented with C-shaped canal while it was absent in 395(49.3\%) about males 40(5\%) with C-shaped canal while 309 (38.6\%) without C-shaped canal).

Furthermore, Figure 2 which is a Bar chart illustrates the prevalence of presence and absence of C-shaped canal in accordance to gender.

To test the hypothesis of impact of gender on occurrence of C-shaped canal, Pearson's Chi-square test performed between the frequency of C-shaped canal in females and males, and no significant difference was found $(P>0.05)$

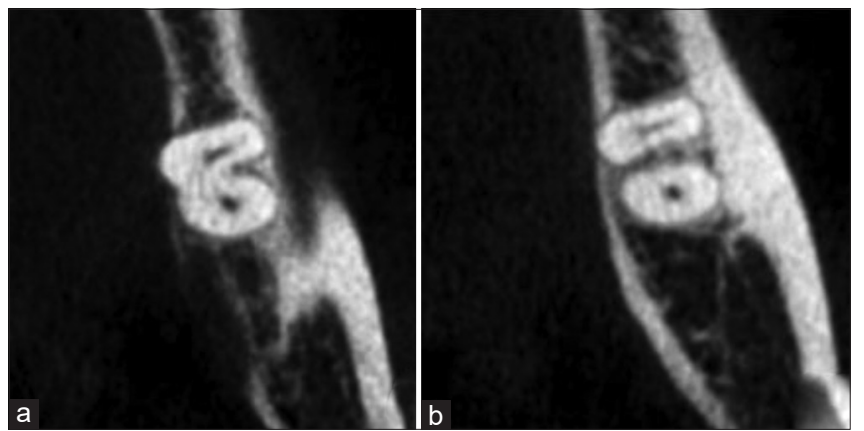

Figure 5: Succession of axial images of a mandibular second molar root: (a) Fused root with $\mathrm{C}$-shaped canal at cervical third. (b) Roots separated at apical third

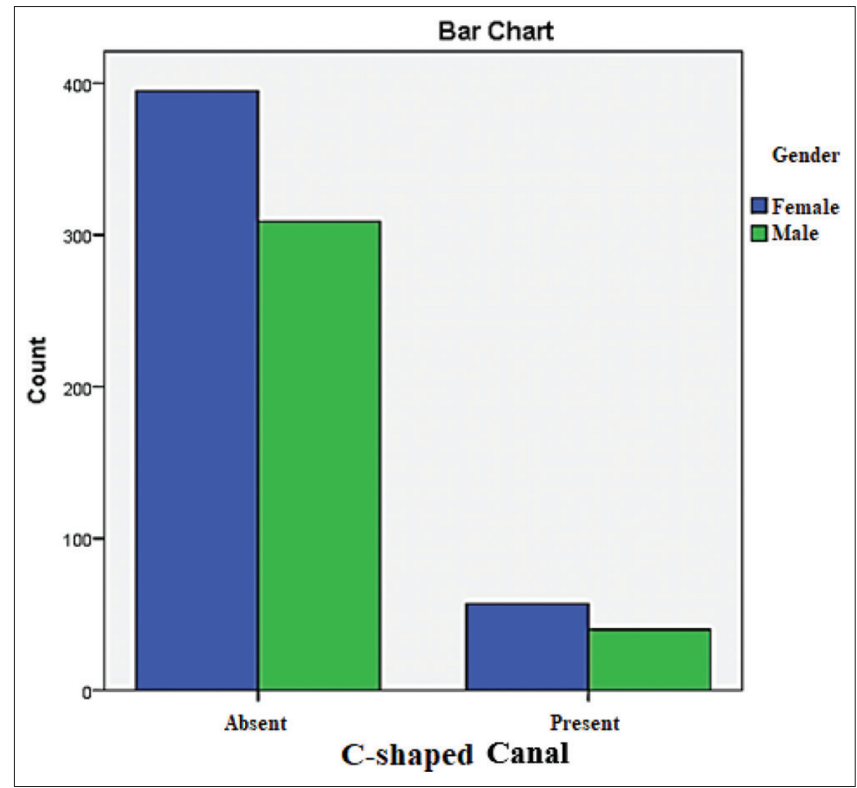

Figure 6: Prevalence of C-shaped canal by gender 


Table 1: The prevalence of the C-shaped canal in mandibular
second molars (\%)
\begin{tabular}{lcc}
\hline Valid & Frequency (percentage) & Frequency (percentage) \\
\hline $\begin{array}{lll}\text { Absent } \\
\text { Female }\end{array}$ & \\
Male & $395(49.3)$ & $704(87.9)$ \\
Present & $309(38.6)$ & \\
Female & $57(7.1)$ & $97(12.1)$ \\
Male & $40(5)$ & \\
Total & $801(100)$ & $801(100)$ \\
\hline
\end{tabular}

\begin{tabular}{|c|c|c|c|c|c|}
\hline & Value & Df & $\begin{array}{l}\text { Asymp. Sig. } \\
\text { (2-sided) }\end{array}$ & $\begin{array}{l}\text { Exact Sig. } \\
\text { (2-sided) }\end{array}$ & $\begin{array}{l}\text { Exact Sig } \\
\text { (1-sided) }\end{array}$ \\
\hline $\begin{array}{l}\text { Pearson } \\
\text { Chi-square }\end{array}$ & $0.244^{\mathrm{a}}$ & 1 & 0.621 & & \\
\hline $\begin{array}{l}\text { Continuity } \\
\text { correction }^{\mathrm{b}}\end{array}$ & 0.148 & 1 & 0.700 & & \\
\hline $\begin{array}{l}\text { Likelihood } \\
\text { ratio }\end{array}$ & 0.245 & 1 & 0.620 & & \\
\hline $\begin{array}{l}\text { Fisher's exact } \\
\text { test }\end{array}$ & & & & 0.663 & 0.351 \\
\hline 801 & & & & & \\
\hline
\end{tabular}

Chi-square tests $(P>0.05)$

as shown in Table 2.

\section{DISCUSSION}

An ideal technique is one that is precise, uncomplicated, nondestructive, and most significantly, feasible in in vivo scenarios (Silva et al., 2013). Based on these components, radiography has been selected for as the foremost viable and as often as possible utilized way to anticipate the root canal anatomy in both laboratory and clinical studies (Neelakantan et al., 2010).

Some studies were utilized micro-CT to inspect root canal morphology. This assessment gives an exact data, but micro-CT cannot be used clinically yet (Liu et al., 2013). Therefore, this study utilized CBCT to assess the canal system configuration of 1567 mandibular $2^{\text {nd }}$ molars in Iraqi individuals to distinguish the prevalence of $\mathrm{C}$-shaped canals.

In literatures, C-shaped root canal configurations were hardly found in Caucasian populations (Cooke and Cox, 1979; Weine, 1998; Cimilli et al., 2005) reported a prevalence of $2.7 \%, 7.6 \%$, and $8.1 \%$ of C-shaped canals, respectively, while Chinese population presented with high prevalence of $\mathrm{C}$-shaped canals, as revealed by Yang et al. (1988), Zheng et al. (2011), and Zhang et al. (2011), (32\%, $39 \%$, and $29 \%$, respectively). The C-shaped canal pointed to be the most common in a Korean subpopulation, with a 31\%-45\% prevalence (Seo and Park, 2004; Seo et al., 2012). These data enhance that canal shape was significantly related to race, with higher prevalence of $\mathrm{C}$-shaped canals in Asians. This occurrence could be justified by presence of a high number of studies in Asian populations and the lack of studies in other populations. In the present study, $12.1 \%$ was the prevalence of the C-shaped canal. A study by Silva et al., in 2013, assessed the canal configurations in a Brazilian subpopulation; they found a 3.5\% prevalence of C-shaped canals in the $2^{\text {nd }}$ mandibular molars which was much less than our study finding.

In this study, no correlation was found between gender and the prevalence of C-shaped canals. These data are comparable to the findings of Zheng et al. (2011) and Shemesh et al. (2017) which they found no significant difference by gender. On the other hand, these data are in controversy to the findings of Sert and Bayirli, (2004) and Martins et al. (2019), which they stated that gender is an important factor to be take into account in the preoperative evaluation of canal morphology for root canal treatment. Proper explanations for the impact of gender on canal configuration can only be found by tracing the genetic ancestry of human mankind 200,000 years ago (Hanihara, 2013). The hypothesis of a morphological genetic adaptation in the Asian populations to fit smallsized teeth into smaller jaws is also supported by several systematic studies reporting morphological differences between individuals of different gender in the same species (Karaman, 2006; Macaluso, 2011; Alvesalo, 2009) and helped to enlighten the high prevalence of C-shaped canal morphology in mandibular second molars of females.

The importance of this study should be highlighted, as it evaluated the configurations of $\mathrm{C}$-shaped canals in a sample of the Iraqi Kurdish subpopulation; however, more studies are necessary, considering that a limitation of this study was conducted on a limited local region and population.

\section{CONCLUSION}

There was a significant prevalence $(12.1 \%)$ of C-shaped canals in the mandibular $2^{\text {nd }}$ molars, with no significant difference by gender. CBCT can be a valuable clinical device for carrying out endodontic diagnosis and treatment when conventional radiographic views create restricted information and further radiographic details are desired for endodontic diagnosis and treatment planning.

\section{REFERENCES}

Al-Fouzan, K. S. 2002. C-shaped root canals in mandibular second molars in a Saudi Arabian population. Int. Endod. J. 35(6): 499- 
504.

Alvesalo, L. 2009. Human sex chromosomes in oral and craniofacial growth. Arch. Oral Biol. 54(1): S18-S24.

Amoroso-Silva, P. A., R. Ordinola-Zapata, M. A. H. Duarte, J. L. Gutmann, A. Del Carpio-Perochena, C. M. Bramante and I. G. de Moraes, I.G. 2015. Micro-computed tomographic analysis of mandibular second molars with c-shaped root canals. J. Endod. 41(6): 890-895.

Cimilli, H., T. Cimilli, G. Mumcu, N. Kartal and P. Wesselink. 2005. Spiral computed tomographic demonstration of C-shaped canals in mandibular second molars. Dentomaxillofac. Radiol. 34(3): 164-167.

Cooke, H. G. $3^{\text {rd }}$. and F. L. Cox. 1979. C-shaped canal configurations in mandibular molars. J. Am. Dent. Assoc. 99(5): 836-839.

Fan, B., G. S. P. Cheung, M. Fan, J. L.Gutmann and Z. Bian. 2004. C-shaped canal system in mandibular second molars: Part I-Anatomical features. J. Endod. 30(12): 899-903.

Haddad, G. Y., W. B. Nehme and H. F. Ounsi. 1999. Diagnosis, classification, and frequency of $\mathrm{C}$-shaped canals in mandibular second molars in the Lebanese population. J. Endod. 25(4): 268-271.

Hanihara, T. 2013. Geographic structure of dental variation in the major human populations of the world. In: Scott, G. R. and J. D. Irish, editors. Anthropological Perspectives on Tooth Morphology. Cambridge University Press, Cambridge. p479-509.

Helvacioglu-Yigit, D. and A. Sinanoglu. 2013. Use of cone-beam computed tomography to evaluate $\mathrm{C}$-shaped root canal systems in mandibular second molars in a Turkish subpopulation: A retrospective study. Int. Endod. J. 46(11): 1032-1038.

Hunter, J. and W. Combe. 1778. The Natural History of the Human Teeth: Explaining their Structure, Use, Formation, Growth, and Diseases. Practical Treatise on the Diseases of the Teeth. Nabu Press, United States.

Jin, G. C., S. J. Lee and B. D. Roh. 2006. Anatomical study of C-shaped canals in mandibular second molars by analysis of computed tomography. J. Endod. 32(1): 10-13.

Karaman, F. 2006. use of diagonal teeth measurements in predicting gender in a Turkish population. J. Forensic Sci. 51(3): 630-635.

Keith, A. 1913. Problems relating to the teeth of the earlier forms of prehistoric man. Proc. R. Soc. Med. 6: 103-124.

Keith, A. and F. H. Knowles. 1911. A description of teeth of palaeolithic man from Jersey. J. Anat. Physiol. 46(1): 12-27.

Liu, N., X. Li, N., Liu, L., Ye, J., An, X., Nie, L., Liu and M. Deng. 2013. A micro-computed tomography study of the root canal morphology of the mandibular first premolar in a population from southwestern China. Clin. Oral Investig. 17(3): 999-1007.

Macaluso, P. J. 2011. Investigation on the utility of permanent maxillary molar cusp areas for sex estimation. Forensic Sci. Med. Pathol. 7(3): 233-247.

Malpighi, M. 1743. Opera Medica, et Anatomica Varia: Quibus Praefationes, and Animadversiones Addidit, Pluribusque in Locis Emendationes Instituit Faustinus Gavinellus Publicus Anatomiae Lector. Nabu Press, Venetiis.

Manning, S. A. 1990. Root canal anatomy of mandibular second molars. Int. Endod. J. 23(1): 40-45.

Martins, J. N. R., D. Marques, E. J. N. Silva, J. Caramês, A. Mata and M. A. Versiani. 2019. Prevalence of C-shaped canal morphology using cone beam computed tomography-a systematic review with meta-analysis. Int. Endod. J. 52(11): 1556-1572.

Neelakantan, P., C.,Subbarao, R., Ahuja, C. V. Subbarao and J. L. Gutmann. 2010. Cone-beam computed tomography study of root and canal morphology of maxillary first and second molars in an Indian population. J. Endod. 36(10): 1622-1627.

Seo, D. G., Y. Gu, Y. A. Yi, S. J. Lee, J. S. Jeong, Y. Lee, S. W. Chang, J. K. Lee, W. Park, K. D. Kim and K. Y. Kum. 2012. A biometric study of C-shaped root canal systems in mandibular second molars using cone-beam computed tomography. Int. Endod. J. 45(9): 807-814.

Seo, M. S. and D. S. Park. 2004. C-shaped root canals of mandibular second molars in a Korean population: Clinical observation and in vitro analysis. Int. Endod. J. 37(2): 139-144.

Sert, S. and G. S. Bayirli. 2004. Evaluation of the root canal configurations of the mandibular and maxillary permanent teeth by gender in the Turkish population. J. Endod. 30(6): 391-398.

Shemesh, A., A. Levin, V. Katzenell, J. Ben Itzhak, O. Levinson, Z. Avraham and M. Solomonov. 2017. C-shaped canalsprevalence and root canal configuration by cone beam computed tomography evaluation in first and second mandibular molars-a cross-sectional study. Clin. Oral Investig. 21(6): 2039-2044.

Silva, E. J. N., Y. Nejaim, A. V. Silva, F. Haiter-Neto and N. Cohenca. 2013. Evaluation of root canal configuration of mandibular molars in a Brazilian population by using cone-beam computed tomography: An in vivo study. J. Endod. 39(7): 849-852.

Vertucci, F. J. 1984. Root canal anatomy of the human permanent teeth. Oral Surg. Oral Med. Oral Pathol. 58(5): 589-599.

von Zuben, M., J. N. R. Martins, L. Berti, I. Cassim, D. Flynn, J. A. Gonzalez, Y. Gu, J. Kottoor, A. Monroe, R. Rosas Aguilar, M. S. Marques and A. Ginjeira. 2017. Worldwide prevalence of mandibular second molar c-shaped morphologies evaluated by cone-beam computed tomography. J. Endod. 43(9): 1442-1447.

Wang, Y., Q. Zheng, X. Zhou, L. Tang, Q. Wang, G. Zheng and D. Huang. 2010. Evaluation of the root and canal morphology of mandibular first permanent molars in a Western Chinese population by cone-beam computed tomography. J. Endod. 36(11): 1786-1789.

Weine, F. S. 1998. The C-shaped mandibular second molar: Incidence and other considerations. J. Endod. 24(5): 372-375.

Yang, Z. P., S. F.Yang, Y. C. Lin, J. C. Shay and C. Y. Chi. 1988. C-shaped root canals in mandibular second molars in a Chinese population. Dent. Traumatol. 4(4): 160-163.

Zhang, R., H. Wang, Y. Y. Tian, X. Yu, T. Hu and P. M. H. Dummer. 2011. Use of cone-beam computed tomography to evaluate root and canal morphology of mandibular molars in Chinese individuals. Int. Endod. J. 44(11): 990-999.

Zheng, Q., L. Zhang, X. Zhou, Q. Wang, Y. Wang, L. Tang, F. Song and D. Huang. 2011. C-shaped root canal system in mandibular second molars in a Chinese population evaluated by cone-beam computed tomography. Int. Endod. J. 44(9): 857-862. 